\title{
High-Temperature Interaction of Liquid Gd with $\mathrm{Y}_{2} \mathrm{O}_{3}$
}

\author{
P. Turalska, N. Sobczak, G. Bruzda, I. Kaban, and N. Mattern
}

(Submitted December 28, 2018; published online March 5, 2019)

\begin{abstract}
The sessile drop method combined with contact heating procedure was applied for the investigation of hightemperature interaction between liquid $\mathrm{Gd}$ and $\mathrm{Y}_{2} \mathrm{O}_{3}$ substrate. Real-time behavior of Gd sample in flowing inert gas (Ar) atmosphere upon heating to and at temperature of $1362{ }^{\circ} \mathrm{C}$ was recorded using high-speed high-resolution CCD camera. The results evidenced that molten Gd wets $\mathrm{Y}_{2} \mathrm{O}_{3}$ substrate (the contact angle $\left.\theta<90^{\circ}\right)$ immediately after melting of metal sample observed at $T=1324{ }^{\circ} \mathrm{C}\left(T_{\mathrm{m}}=1312{ }^{\circ} \mathrm{C}\right)$. During the first $3 \mathrm{~min}$ of the sessile drop test, the contact angle dropped from $\theta=52^{\circ}$ to $\theta=24^{\circ}$ and then stabilized at the final value of $\theta_{\mathrm{f}}^{*}=33^{\circ}$. The solidified $\mathrm{Gd} / \mathrm{Y}_{2} \mathrm{O}_{3}$ couple was subjected to structural characterization using optical microscopy, scanning electron microscopy coupled with $x$-ray energy-dispersive spectroscopy. The results evidenced that the wettability in the $\mathrm{Gd} / \mathrm{Y}_{2} \mathrm{O}_{3}$ system has a reactive nature and the leading mechanism of the interaction between liquid $\mathrm{Gd}$ and $\mathrm{Y}_{2} \mathrm{O}_{3}$ is the dissolution of the ceramic in the liquid metal responsible for the formation of a deep crater in the substrate under the drop. Therefore, the final contact angle $\theta_{\mathrm{f}}^{*}$, estimated from the side-view drop image, should be considered as an apparent value, compared to the more reliable value of $\theta_{\mathrm{f}}=70^{\circ}$ measured on the cross section of the solidified couple.
\end{abstract}

Keywords Gd, interfaces, reactivity, sessile drop, wettability, $\mathrm{Y}_{2} \mathrm{O}_{3}$

\section{Introduction}

The development of metallic materials technology, especially alloys with highly reactive components, is inextricably linked to the search for new, refractory ceramic materials for crucible-assisted melting and casting processes. Such ceramics must be characterized by a set of features, e.g., good mechanical strength, high erosion and corrosion resistance to molten metals, and low levels of impurities, which could significantly affect the metal properties upon entering into the melt. The same requirements apply for materials of containers (e.g., crucibles, holders, and capillaries) used for measurements of thermophysical properties of liquid and semisolid alloys; those reliable values are particularly important in modeling and computer simulation of liquid-assisted processes. Examples include widely used calorimetric, dilatometric, and thermo-

This article is an invited submission to JMEP selected from presentations at the 73rd World Foundry Congress and has been expanded from the original presentation. 73WFC was held in Krakow, Poland, September 23-27, 2018, and was organized by the World Foundry Organization and Polish Foundrymen's Association.

Electronic supplementary material The online version of this article (https://doi.org/10.1007/s11665-019-03954-y) contains supplementary material, which is available to authorized users.

P. Turalska and G. Bruzda, Foundry Research Institute, 73 Zakopianska Str., 30-418 Krakow, Poland; N. Sobczak, Foundry Research Institute, 73 Zakopianska Str., 30-418 Krakow, Poland; and Institute of Precision Mechanics, 3 Duchnicka Str., 01-796 Warsaw, Poland; and I. Kaban and N. Mattern, Institute for Complex Materials, IFW Dresden, Helmholtzstraße 20, 01069 Dresden, Germany. Contact e-mail: patrycja.turalska@iod.krakow.pl. gravimetric tests as well as measurements of electrical and thermal conductivity, surface tension, and density of liquid metals and alloys. The characteristic feature of containerassisted methods is a relatively long time of contact of the melt with the container material.

In the available literature, there is no information on a chemically stable material that could be used for hightemperature contact with gadolinium, although quite different refractories have been reported to be used in the works where Gd-rich alloys or Gd-containing compounds were synthesized or examined at high temperatures using container-assisted methods (Ref 1-9).

Waring and Schneider deposited the $\mathrm{Gd}_{2} \mathrm{O}_{3}-\mathrm{TiO}_{2}$ compounds by heating them in air at $1000{ }^{\circ} \mathrm{C}$ and placed samples on platinum plates (Ref 1), while Klimm et al. used platinum crucibles for DTA studies of $\mathrm{LiREF}_{4}$ materials $(\mathrm{RE}=\mathrm{Eu}, \mathrm{Gd}$, $\mathrm{Tb}, \mathrm{Dy}, \mathrm{Ho}$ ) at temperatures up to $1300{ }^{\circ} \mathrm{C}$ (Ref 2). Literature has also documented the use of crucibles made of aluminum oxide $\left(\mathrm{Al}_{2} \mathrm{O}_{3}\right)$ for DTA studies of gadolinium-containing materials. They were used by both Wang et al. for the $\mathrm{ZrO}_{2}$ $\mathrm{REO}_{1.5}$ system $(\mathrm{RE}=\mathrm{La}, \mathrm{Nd}, \mathrm{Sm}, \mathrm{Gd}, \mathrm{Dy}, \mathrm{Yb})$ at temperatures up to $1700{ }^{\circ} \mathrm{C}$ (Ref 3 ) and S. Schmitz et al. for the Gd-Ti and Gd-Ti-Al-Cu alloys at $1300{ }^{\circ} \mathrm{C}(\operatorname{Ref} 4)$. None of these works, however, clearly indicates the ceramic materials suitable for the melting or testing of molten gadolinium-rich alloys.

According to analysis of literature data, there are a few oxides widely used in high-temperature refractory materials: $\mathrm{Y}_{2} \mathrm{O}_{3}, \mathrm{Gd}_{2} \mathrm{O}_{3}, \mathrm{Al}_{2} \mathrm{O}_{3}, \mathrm{ZrO}_{2}, \mathrm{TiO}_{2}$. Based on the Ellingham diagram of the stability of selected oxides (Ref 10 ), it may be concluded that $\mathrm{Y}_{2} \mathrm{O}_{3}$ should be the most stable oxide and that it should exhibit the lowest reactivity with liquid $\mathrm{Gd}$, as the decrease in oxide stability occurs in the following order of refractory oxides:

$$
\mathrm{Y}_{2} \mathrm{O}_{3} \rightarrow \mathrm{Gd}_{2} \mathrm{O}_{3} \rightarrow \mathrm{Al}_{2} \mathrm{O}_{3} \rightarrow \mathrm{ZrO}_{2} \rightarrow \mathrm{TiO}_{2}
$$

However, the preliminary study of interaction of liquid $\mathrm{Gd}$ with $\mathrm{Y}_{2} \mathrm{O}_{3}, \mathrm{ZrO}_{2}-3$ wt. $\% \mathrm{Y}_{2} \mathrm{O}_{3}$ (3YSZ), and $\mathrm{TiO}_{2}$ substrates reported by Sobczak et al. (Ref 6) showed that unexpectedly among these oxides, $\mathrm{Y}_{2} \mathrm{O}_{3}$ exhibits the highest reactivity in 
contact with liquid Gd. Moreover, the study (Ref 6) confirmed the first findings on yttria-based ceramics $\mathrm{Y}_{2} \mathrm{O}_{3}, \mathrm{ZrO}_{2}$ 3 wt. $\% \mathrm{Y}_{2} \mathrm{O}_{3}$ (3YSZ), and $\mathrm{ZrO}_{2}-5$ wt. $\% \mathrm{Y}_{2} \mathrm{O}_{3}$ (5YSZ) reported by Kaban et al. (Ref 7) and showing that the reactivity of yttriastabilized zirconia with Gd-based alloys containing Ti increases with the increase in the amount of $\mathrm{Y}_{2} \mathrm{O}_{3}$. Therefore, both $\mathrm{Y}_{2} \mathrm{O}_{3}$ and 5YSZ were excluded as refractories suitable for measurements of the thermophysical properties of Gd-Ti alloys by substrate- or container-assisted technique in work (Ref 7).

Recent study by Turalska et al. (Ref 8) on the hightemperature behavior and the reactivity of $\mathrm{Gd} / 3 \mathrm{YSZ}$ couple in flowing Ar showed that liquid gadolinium wets $3 \mathrm{YSZ}$ with the final contact angle of $67^{\circ}$ at 1362 and $1412{ }^{\circ} \mathrm{C}$. Good wettability was explained by the formation of a continuous layer of the wettable reaction product $\mathrm{Gd}_{2} \mathrm{Zr}_{2} \mathrm{O}_{7}$, growing at the drop/substrate interface as well as on the substrate surface beyond the drop. The same authors examined the wettability of dense $\mathrm{TiO}_{2}$ substrates with liquid Gd (Ref 9) using the identical testing conditions as those applied in the research described in Ref 8 ). The results of wetting tests of the $\mathrm{Gd} / \mathrm{TiO}_{2}$ couple show that liquid $\mathrm{Gd}$ does not wet $\mathrm{TiO}_{2}$ substrate and that it forms high contact angles of $\theta \sim 100^{\circ}$ at both $1362{ }^{\circ} \mathrm{C}$ and $1412{ }^{\circ} \mathrm{C}$. It was also observed that in the $\mathrm{Gd} / 3 \mathrm{YSZ}$ as well as in the $\mathrm{Gd} /$ $\mathrm{TiO}_{2}$ couples, the interaction of $\mathrm{Gd}$ with the ceramic leads to the formation of an interfacial layer and is accompanied by the dissolution of the substrate in the liquid drop. Important difference is in the structure of reactively formed interfacial layer. In the $\mathrm{Gd} / 3 \mathrm{YSZ}$ couple, it represents one single-phase $\mathrm{Gd}_{2} \mathrm{Zr}_{2} \mathrm{O}_{7}$ while in the $\mathrm{Gd} / \mathrm{TiO}_{2}$ couple, it is composed of two sublayers with different structure and chemical composition: $\mathrm{Gd}_{2} \mathrm{TiO}_{5}$ in the drop side sublayer and $\mathrm{Gd}_{2} \mathrm{Ti}_{2} \mathrm{O}_{7}$ in the substrate-side sublayer.

In this work, high-temperature interaction between pure $\mathrm{Gd}$ and polycrystalline $\mathrm{Y}_{2} \mathrm{O}_{3}$ was examined using the sessile drop method following the testing procedure already used in studies (Ref 8, 9).

\section{Experimental}

The materials used were pure Gd of $99.99 \%$ purity (SigmaAldrich) and polycrystalline $\mathrm{Y}_{2} \mathrm{O}_{3}$ substrate made by highpressure, high-temperature synthesis. The $\mathrm{Y}_{2} \mathrm{O}_{3}$ substrate was polished to a roughness of $R_{\mathrm{a}} \approx 120 \mathrm{~nm}$ and then ultrasonically cleaned in isopropanol $\left(\mathrm{C}_{3} \mathrm{H}_{8} \mathrm{O}\right.$ alcohol $)$ for $5 \mathrm{~min}$. Directly before the high-temperature test, the substrate was preheated in air at $1700{ }^{\circ} \mathrm{C}$ for $2 \mathrm{~h}$.

The sessile drop method was applied for investigation of high-temperature wetting behavior and reactivity between liquid $\mathrm{Gd}$ and $\mathrm{Y}_{2} \mathrm{O}_{3}$ substrate using an experimental set up described in details in Ref 11. During the high-temperature test, the $\mathrm{Gd} / \mathrm{Y}_{2} \mathrm{O}_{3}$ couple was contact-heated to the test temperature of $T_{\exp }=1362{ }^{\circ} \mathrm{C}$ with a heating rate of $12{ }^{\circ} \mathrm{C} / \mathrm{min}$ under flowing inert gas (Ar, 99.9992\%) under a pressure of 850$900 \mathrm{hPa}$. After isothermal heating at $T_{\exp }$ for $5 \mathrm{~min}$, the couple was cooled down to the room temperature at a rate of $24{ }^{\circ} \mathrm{C} /$ $\min$.

The behavior of the Gd sample on ceramic substrate was registered using an MC1310 high-speed, high-resolution digital camera. In the first stage of the experiment, including heating until sample melting and isothermal heating of the couple at $1362{ }^{\circ} \mathrm{C}$, the couple behavior was recorded at a rate of 10 frames per second (fps). The next stage, which involved cooling to the solidification temperature, was recorded at a rate of $1 \mathrm{fps}$. The collected images were used for estimation of the contact angle values $\theta\left(\theta_{\mathrm{l}}\right.$ - left-side angle; $\theta_{\mathrm{r}}$-right-side angle and $\theta$ - average value of $\theta_{1}$ and $\theta_{\mathrm{r}}$ ) with a help of the ASTRA2 software developed by ICMATE-CNR, Genoa, Italy (Ref 12, 13) as well as for making a real-time movie of the hightemperature test (SUPPLEMENT \#1).

Structural and chemistry characterization of solidified couple was made both on its top surface and on cross section using Keyence VHX-700F optical microscope (OM) and Hitachi TM3000 scanning electron microscope (SEM) equipped with energy-dispersive x-ray spectroscopy (EDS) analyzer.

\section{Results}

A wetting kinetic curve as $\theta$ versus time for the $\mathrm{Gd} / \mathrm{Y}_{2} \mathrm{O}_{3}$ couple is shown in Fig. 1, while the values of the contact angle corresponding to critical moments of the high-temperature interaction between the contacting materials are summarized in Table 1. During heating of the system to $T_{\exp }=1362{ }^{\circ} \mathrm{C}$, liquid

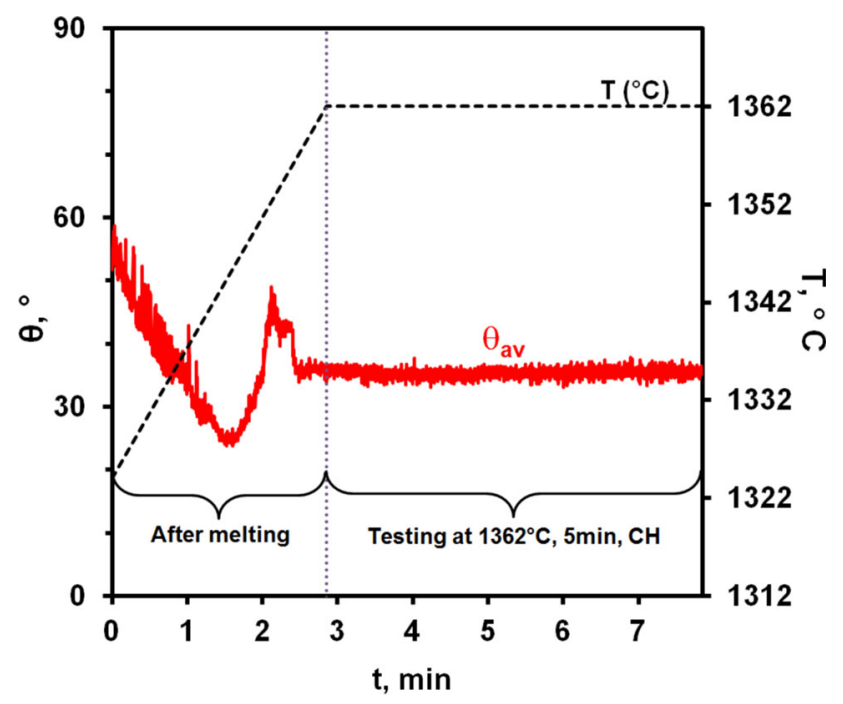

Fig. 1 Wetting kinetics of the molten $\mathrm{Gd}$ on the $\mathrm{Y}_{2} \mathrm{O}_{3}$ substrate; $\mathrm{T}_{\mathrm{m}}(\mathrm{Gd})=1312{ }^{\circ} \mathrm{C}$

Table 1 Contact angle values calculated and measured for the $\mathrm{Gd} / \mathrm{Y}_{2} \mathrm{O}_{3}$ system

\begin{tabular}{lcc}
\hline $\boldsymbol{T}_{\text {exp }},{ }^{\circ} \mathrm{C}$ & Contact angle $\boldsymbol{\theta},{ }^{\circ}$ \\
\hline 1324 & $\theta_{0}^{*}$ & 52 \\
1362 & $\theta_{0}$ & 33 \\
$\theta_{\mathrm{f}}^{*}$ & 33 \\
$\theta_{\mathrm{f}}$ & 70 \\
$\theta_{0} *$ - contact angle formed immediately after melting \\
$\theta_{0}$-contact angle in $t=0 \mathrm{~s}$ at $T_{\text {exp }}=1362{ }^{\circ} \mathrm{C}$ \\
$\theta_{\mathrm{f}}^{*}$ - final apparent contact angle calculated from the drop image at \\
$T_{\text {exp }}$ the contact angle value after interaction at $T_{\text {exp }}=1362{ }^{\circ} \mathrm{C}$ for \\
$\theta_{\mathrm{f}}$-the \\
5 min, measured on the cross section of solidified couple \\
\hline
\end{tabular}


Gd wets the $\mathrm{Y}_{2} \mathrm{O}_{3}$ substrate immediately after its melting observed at a temperature $T=1324{ }^{\circ} \mathrm{C}$, which is higher than the melting point of $\mathrm{Gd}\left(T_{\mathrm{m}}=1312^{\circ} \mathrm{C}\right)$ due to the presence of primary oxide film on the $\mathrm{Gd}$ sample. The first contact angle recorded at $T=1324{ }^{\circ} \mathrm{C}$ (i.e., corresponding to $t=0 \mathrm{~min}$ ) was $\theta_{0} * \sim 52^{\circ}$. During further heating to the test temperature, the

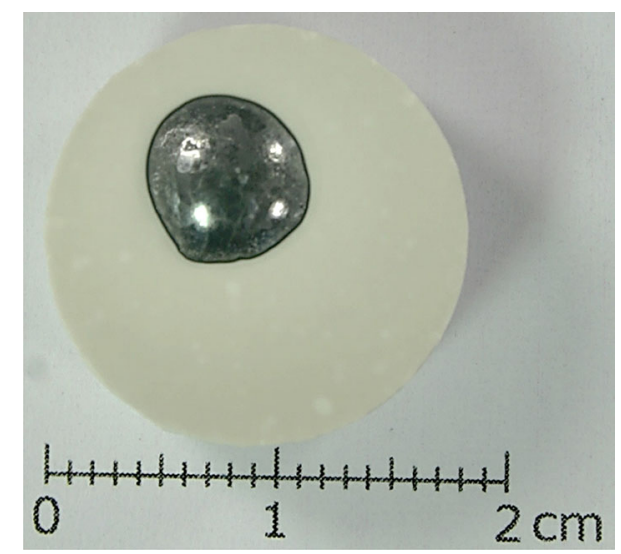

Fig. 2 A top-view photograph of the solidified $\mathrm{Gd} / \mathrm{Y}_{2} \mathrm{O}_{3}$ couple contact angle decreased to $\theta=24^{\circ}$ in $1.5 \mathrm{~min}$ after melting, when temperature was $1344{ }^{\circ} \mathrm{C}$. Fluctuations of contact angle values, visible on the curve of the wetting kinetics during this stage of the sessile drop test, are related with the change in the shape of Gd sample during its melting, as evidenced in direct observations of the behavior of the couple in the wetting test (SUPPLEMENT \#1). Most probably, the presence of primary oxide film on the Gd drop that affects its symmetrical shaping during heating, is responsible for further increase in the contact angle to a value of $\theta=49^{\circ} \quad(t=2.2 \mathrm{~min}$ after melting, $T=1354{ }^{\circ} \mathrm{C}$ ). However, after $2.7 \mathrm{~min}$ from melting, the contact angle decreased again and stabilized at a value of $\theta=33^{\circ}$ at $T=1355^{\circ} \mathrm{C}$, i.e., before reaching the test temperature of $1362{ }^{\circ} \mathrm{C}$.

Isothermal heating of the system at the test temperature $T_{\exp }=1362{ }^{\circ} \mathrm{C}$ for $5 \mathrm{~min}$ (Fig. 1) does not affect the contact angle and the persistent averaged value of $33^{\circ}$ suggests that the $\mathrm{Gd} / \mathrm{Y}_{2} \mathrm{O}_{3}$ system has achieved its thermodynamic equilibrium before reaching the test temperature. This fact combined with the low value of the final contact angle recorded in this study $\theta_{\mathrm{f}}{ }^{*}=33^{\circ}$ is typical for systems with high reactivity.

The top view of solidified $\mathrm{Gd} / \mathrm{Y}_{2} \mathrm{O}_{3}$ couple after the wetting test is shown in Fig. 2. The $\mathrm{Y}_{2} \mathrm{O}_{3}$ substrate did not change its initially white color after the high-temperature exposition.
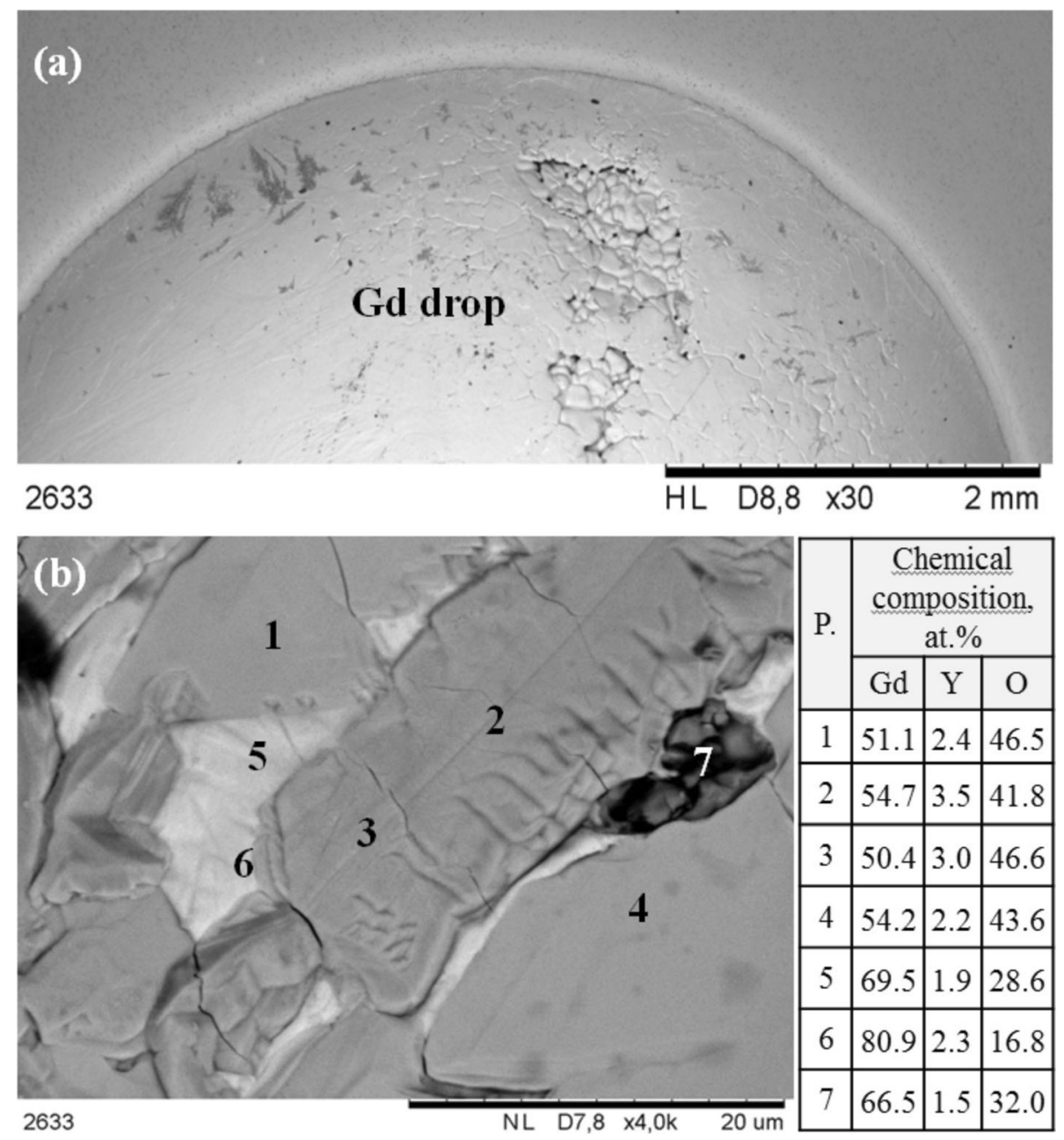

Fig. 3 SEM top-view images of the drop surface after the wetting test under different magnification: (a) $30 \times$; (b) $4000 \times$; image (b) shows to the drop surface with corresponding EDS analysis 

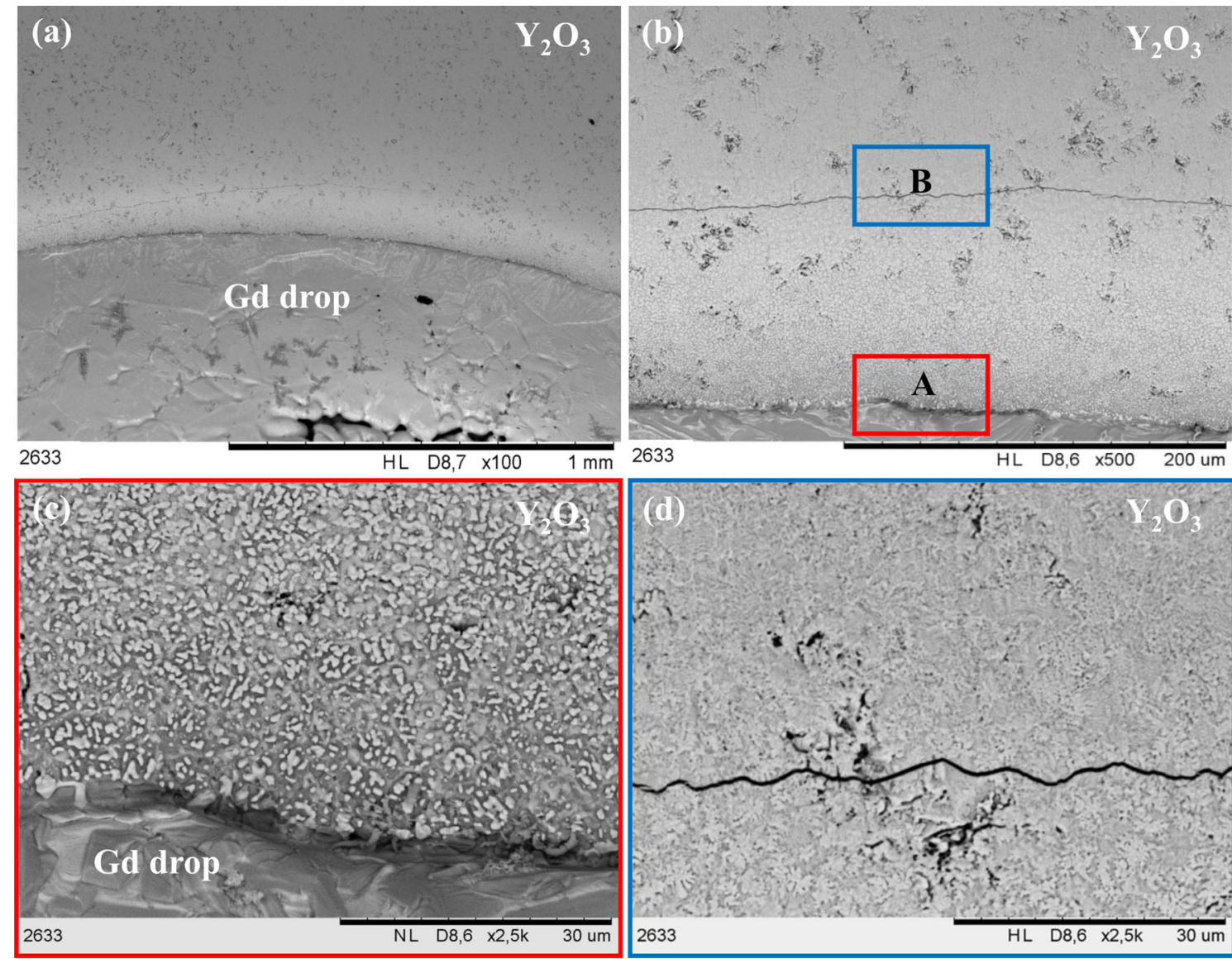

Fig. 4 SEM top-view images of the substrate surface after the wetting tests (a-b); the (A) section—near the drop (c); the (B) section—far from the drop $(d)$
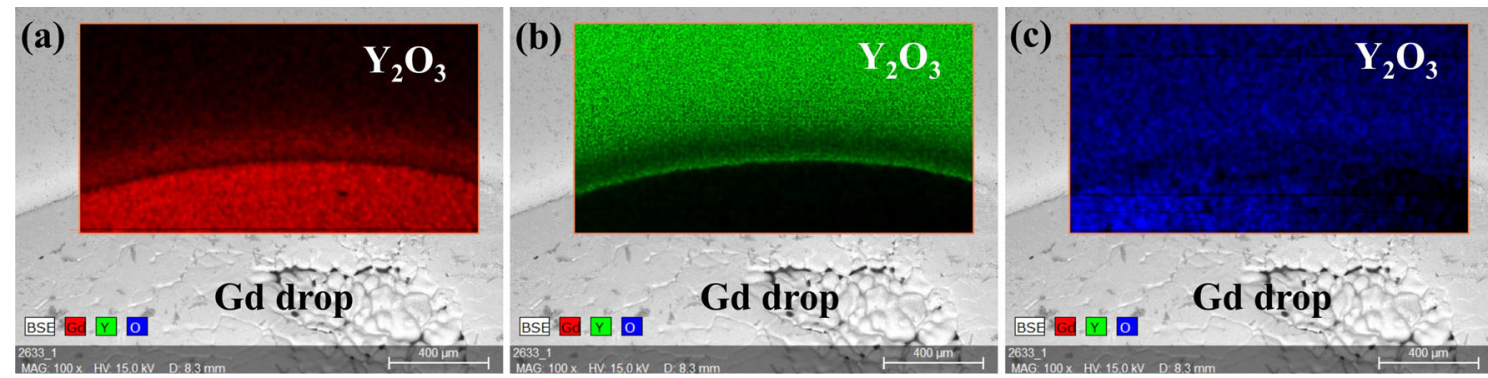

Fig. 5 EDS analysis: distribution of individual elements on the top-view surface of the solidified $\mathrm{Gd} / \mathrm{Y}_{2} \mathrm{O}_{3}$ couple after the wetting tests: (a) gadolinium; (b) yttrium; (c) oxygen

Solidified drop has an asymmetrical shape, and it is surrounded with a black ring. Additionally, the presence of bright and dark areas on the drop surface indicates its inhomogeneous structure.

The drop inhomogeneity in the microstructure was confirmed by top-view SEM examinations (Fig. 3a and b), in which fine particles appeared on the entire drop surface as black spots, as shown in Fig. 3(a). More detailed chemical and structural examinations carried out at magnification of $4000 \times$ revealed that these particles mainly contain gadolinium, oxygen and small amount of yttrium (Fig. 3, P. 7). Furthermore, large dark-gray precipitates (Fig. 3, P. 1-4) composed of $\mathrm{Gd}, \mathrm{O}$, and up to 3.5 at.\% Y were also found in the Gd matrix containing dissolved oxygen up to 28.6 at. $\%$ and yttrium up to 2.3 at.\% (Fig. 3, P. 5-6).
The results of structural characterization of the substrate after the wetting test (Fig. 4a, b and c) show the changes of surface roughness with increasing the distance from the $\mathrm{Gd}$ drop. Closely packed, coarse-grained precipitates having irregular shapes were found in the vicinity of the Gd drop (Fig. 4c). With increase in the distance from the drop, a structure of these participates became finer (Fig. 4d). Additionally, a few cracks are observed to appear on the surface of the $\mathrm{Y}_{2} \mathrm{O}_{3}$ substrate near the drop (Fig. 4a, b and d). Most probably, they are caused by thermal stresses generated during cooling due to a large CTE mismatch of $\mathrm{Gd}\left(9.4 \times 10^{-6} \mathrm{~K}^{-1}\right)(\mathrm{Ref} 14)$ and $\mathrm{Y}_{2} \mathrm{O}_{3}$ substrate $\left(11 \times 10^{-6} \mathrm{~K}^{-1}\right.$ for $\left.1200^{\circ} \mathrm{C}\right)(\operatorname{Ref} 15)$.

The EDS/SEM characterization of the elements distribution on the substrate surface around the drop (Fig. 5a, b and c) 

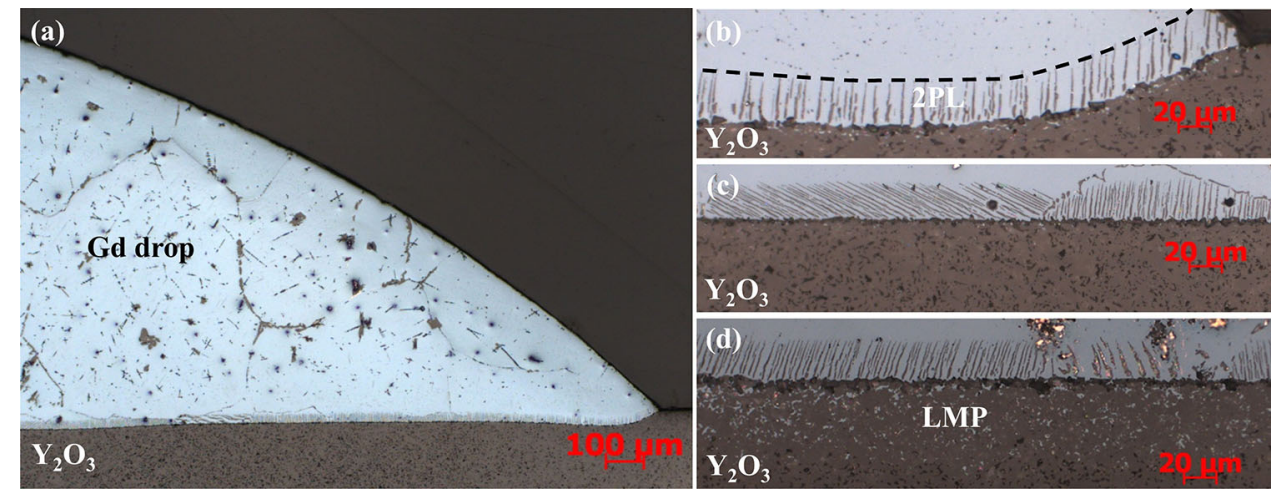

Fig. 6 Microstructure of a cross-sectioned sessile drop sample $(\mathrm{OM})$ : (a) near the triple line $(100 \times)$; (b) crater in the substrate and two-phase layer (2PL), $500 \times$; (c) 2 PL with a different direction of the needles $(500 \times)$; (d) the interface in the central part of the drop and liquid metal penetration $($ LMP) area in the substrate $(500 \times)$

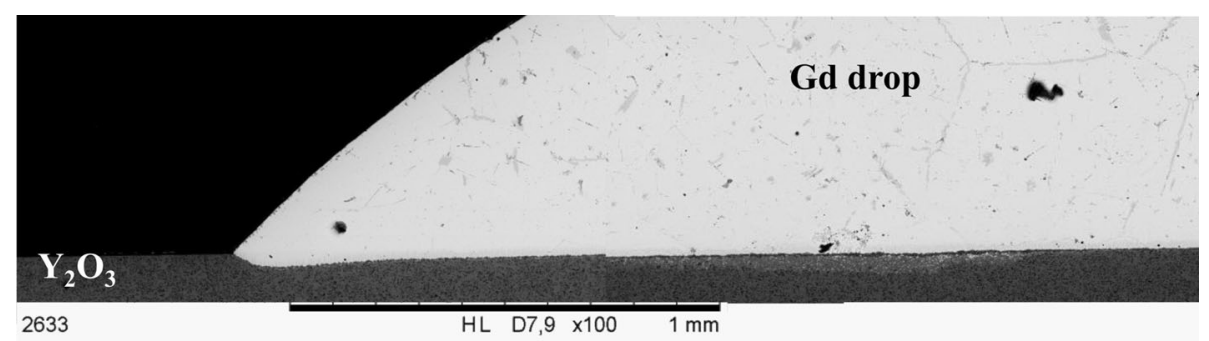

(a)

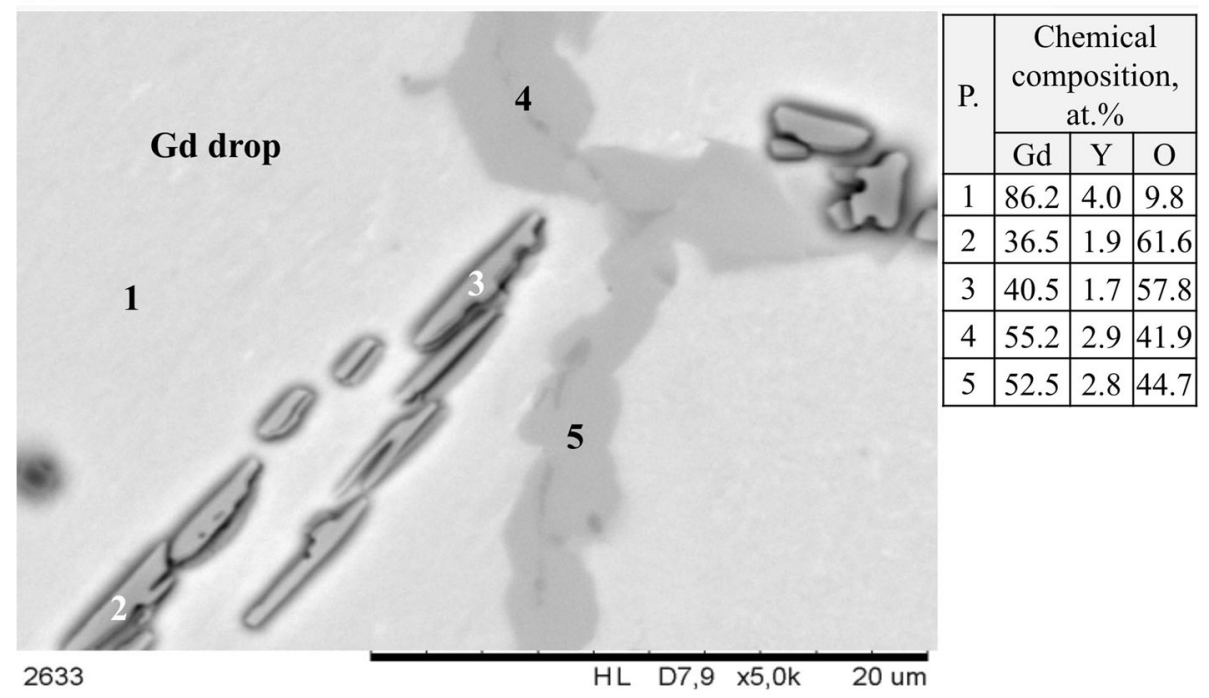

(b)

Fig. 7 SEM images of cross-sectioned $\mathrm{Gd} / \mathrm{Y}_{2} \mathrm{O}_{3}$ couple: (a) general view; (b) the microstructure of the drop and corresponding EDS analysis at the marked points in the central part of the drop

revealed the presence of Gd-rich ring, evidenced also as the black ring visible on a top-view photograph of the solidified $\mathrm{Gd} / \mathrm{Y}_{2} \mathrm{O}_{3}$ couple (Fig. 2). The formation of this ring is associated with the evaporation and deposition of Gd taking place during the sessile drop test.

The results of optical microscopy evaluation of the crosssectioned couple are shown in Fig. 6(a, b, c and d). The microstructure of initially pure Gd becomes inhomogeneous, with different types of precipitates inside the drop. At the grain boundaries, the precipitates with elongated shape are located, while inside the grains the fine, dark-gray precipitates having irregular shape are observed (Fig. 6a). Moreover, there is a crater in the substrate under the drop (Fig. 6a). The crater is filled with solidified metal, and it is covered by a two-phase layer (2PL) of about $30 \mu \mathrm{m}$ thickness formed on the bottom of the crater, which is well distinguished under higher magnifications (Fig. 6b, c and d). It is composed of dark-gray needlelike precipitates growing in light-gray matrix from the substrate 


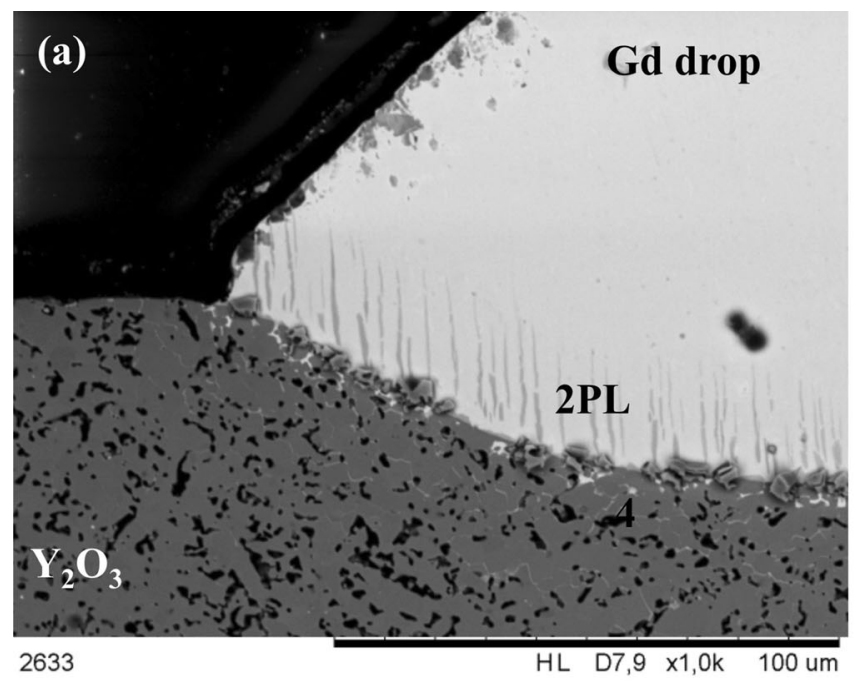

(b)

\section{Gd drop}
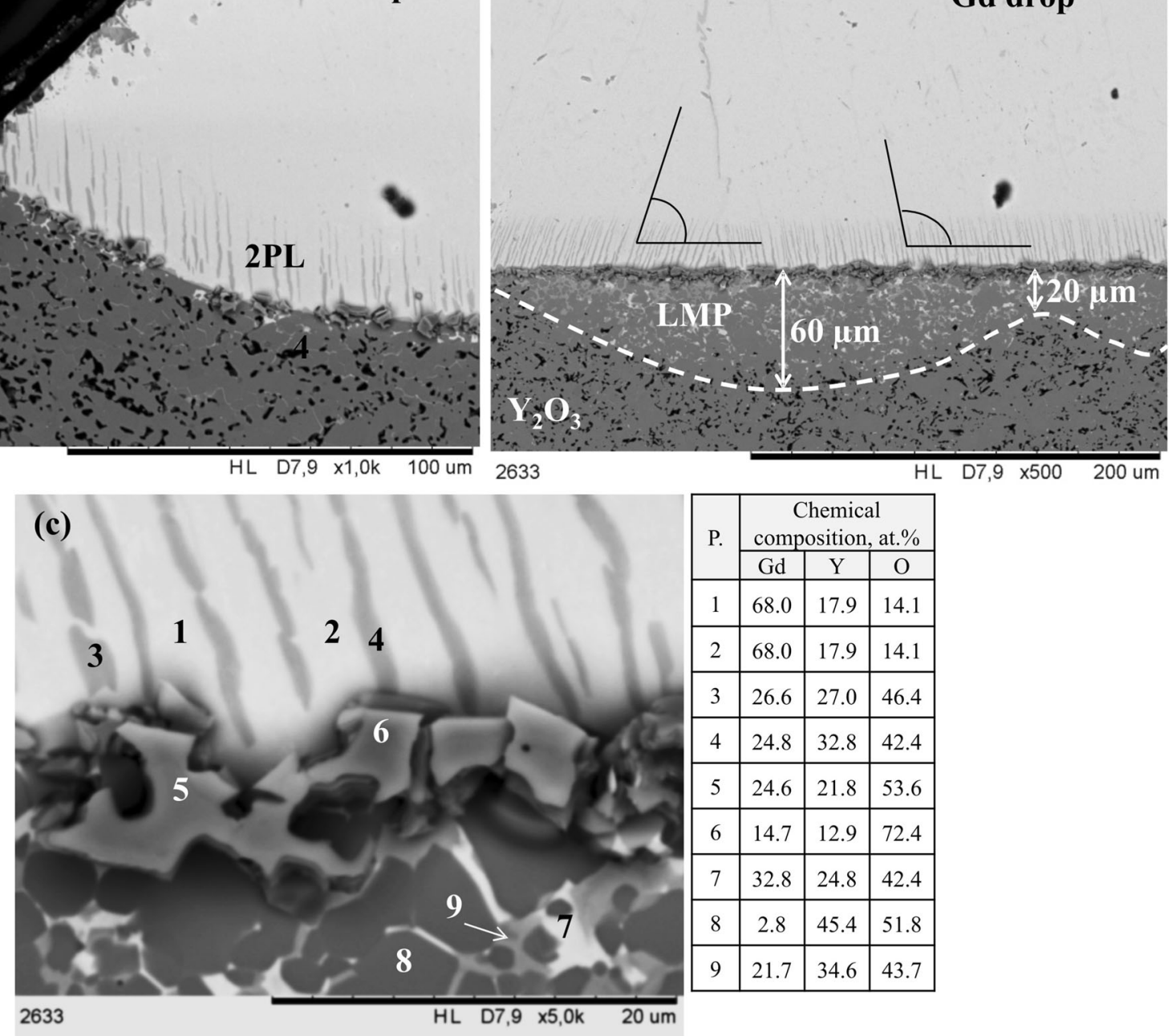

Fig. 8 SEM images of interface structure of cross-sectioned $\mathrm{Gd} / \mathrm{Y}_{2} \mathrm{O}_{3}$ couple: (a) near triple line; (b) central part of the couple; (c) magnified image of (b) with corresponding EDS analysis at the marked points

toward the Gd drop, e.g., in accordance with solidification direction. The orientation of needles inside the 2PL varies depending on the selected observation site (Fig. 6b, c and d).

The structural characterization of the cross-sectioned solidified couple carried out by scanning electron microscopy (Fig. 7a and b) confirmed the optical microscopy observations. Fine precipitates, non-homogenously distributed both inside the grains and along the grain boundaries, are revealed (Fig. 7a). The precipitates located in the center of the matrix (Fig. 7b, P.1) are smaller than those of more elongated shape, observed near the grain boundaries (Fig. 7b, P.2, P.3 and P.4, P.5, respectively). The results of EDS microanalysis of particles located at the grains boundaries showed that they are mostly composed of $\mathrm{Gd}$ and $\mathrm{O}(\mathrm{Gd} / \mathrm{O}$ ratio is $1: 1)$ and small amount of yttrium up to 2.9 at. $\%$. The precipitates observed inside the drop have slightly finer structure and the $\mathrm{Gd} / \mathrm{O}$ ratio of 3:2 (Fig. 7, P.3 and P.4). The drop matrix (Fig. 7b, P.1) represents $\mathrm{Gd}$ with a dissolved O (up to 9.8 at.\%) and Y (up to 4.0 at.\%).

The results of detailed structural characterization accompanied by microanalysis of chemical composition of phases formed at the drop/substrate interface are shown in Fig. 8(a, $\mathrm{b}$ and $\mathrm{c}$ ). The 2PL region formed in the crater under the drop is composed of dark-gray precipitates with a needle-like morphology growing from the substrate toward the Gd drop (Fig. 8a and b). The drop matrix inside the 2PL layer consists of the Gd-based solid solution of $\mathrm{O}$ up to 14.1 at.\% and Y up to 17.9 at.\% (Fig. 8c, P.1 and P.2). The needle-like precipitates were mostly composed of Gd (up to 32.8 at.\%), $\mathrm{Y}$ (up to 26.6 at.\%), and $\mathrm{O}$ (Fig. 8c, P.3 and P.4). Additionally, a discontinuous layer of irregular separated grains was observed at the substrate-side interface (Fig. 8a, b and $\mathrm{c}$ ). Its chemical composition points toward the formation of $(\mathrm{Gd}, \mathrm{Y})_{2} \mathrm{O}_{3}$ phase that dissolves up to 24.6 at.\% of $\mathrm{Y}$ (Fig. 8c, P.5 and P.6). Moreover, the liquid metal penetration (LMP) along the grain boundaries of yttria substrate is also recognized. The LMP zone is characterized by a nonuniform depth of 20 to $60 \mu \mathrm{m}$ (Fig. 8b) and significant Gd enrichment in grain boundaries of the substrate (Fig. 8c, P.7 and P.9), while the substrate itself dissolved up to 2.8 at. $\%$ Gd (Fig. 8c, P.8). 


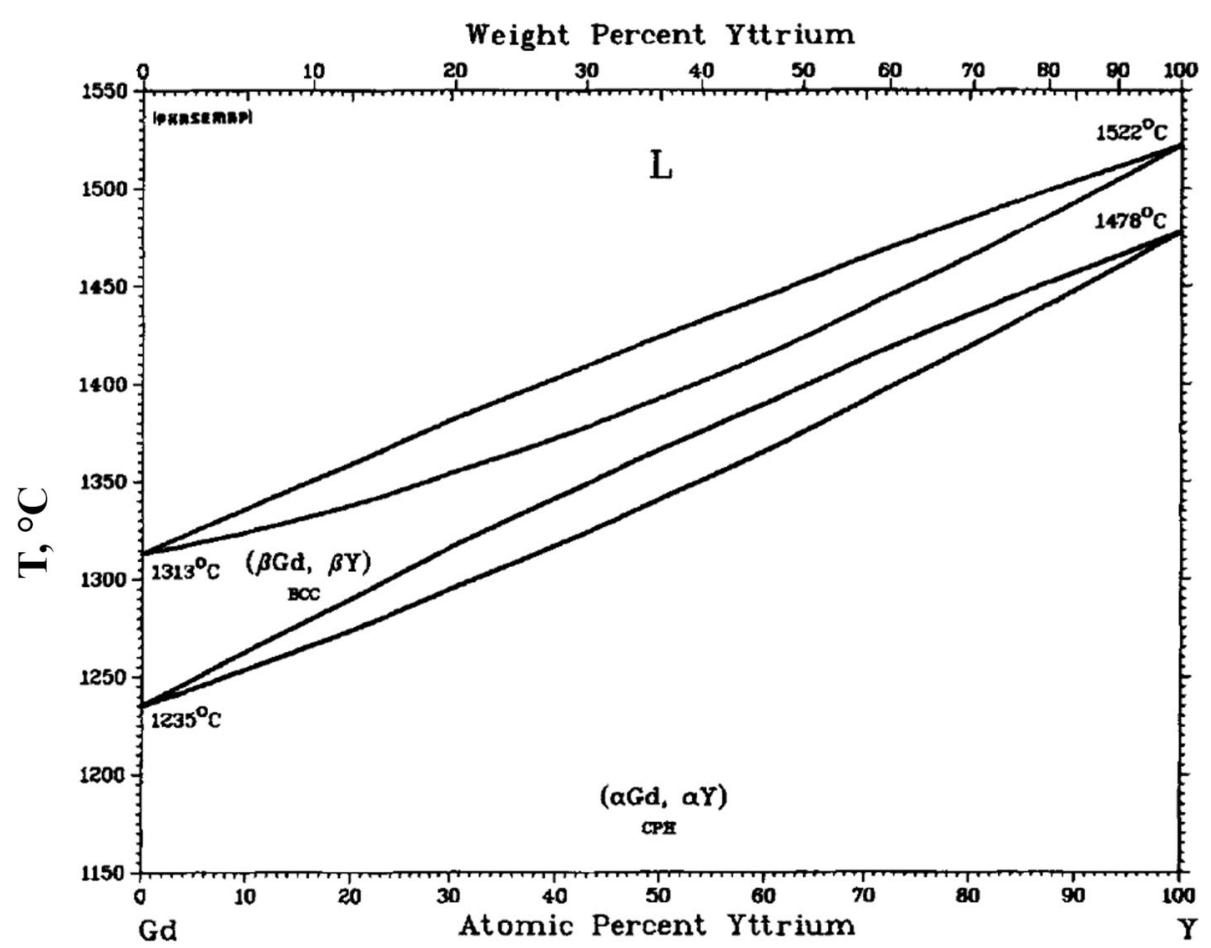

(a)

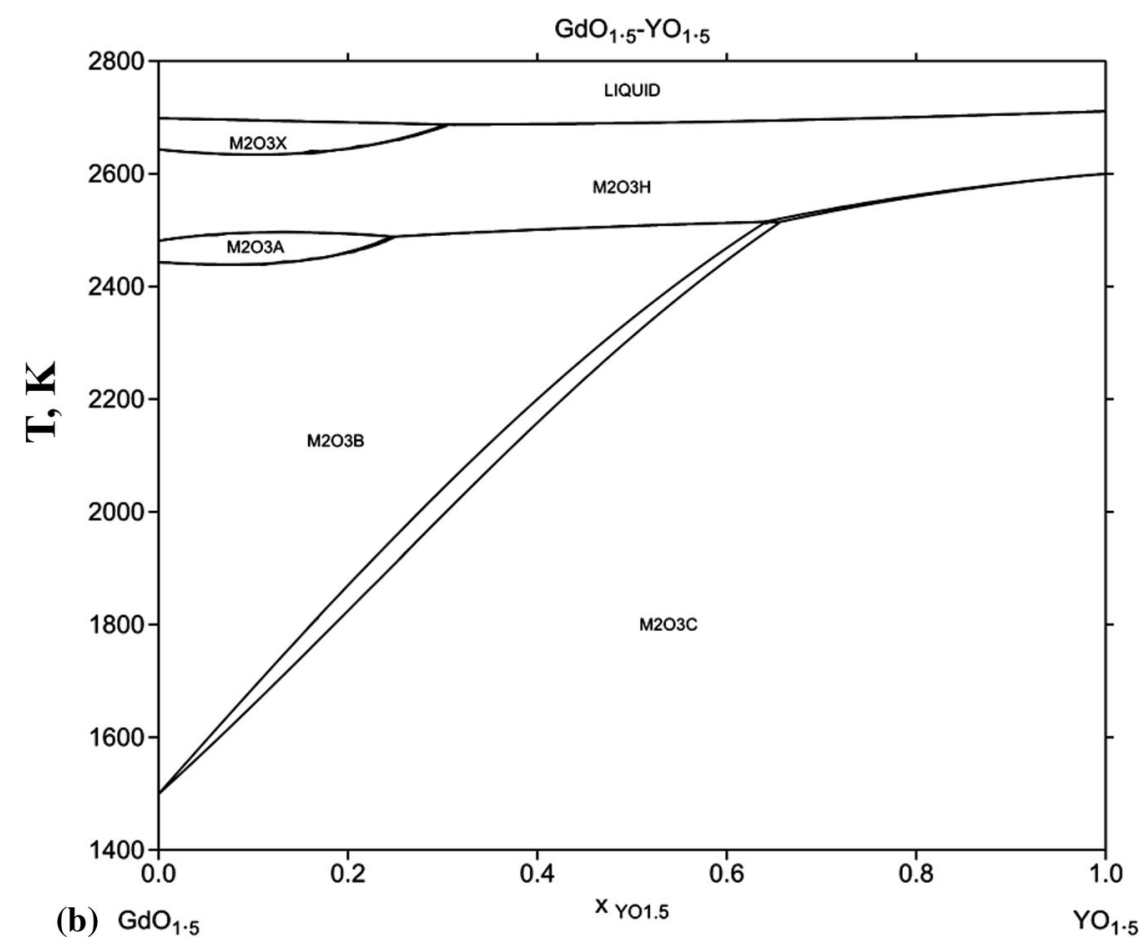

Fig. 9 Equilibrium phase diagrams: (a) Gd-Y (Ref 16); (b) $\mathrm{GdO}_{1.5}-\mathrm{YO}_{1.5}$ (Ref 17) (c) Gd-O (Ref 18)

\section{Discussion}

The analysis of available literature shows a lack of any data on the Gd-Y-O phase equilibria. However, important information about high-temperature interaction in the $\mathrm{Gd} / \mathrm{Y}_{2} \mathrm{O}_{3}$ sessile drop couple can be inferred from the binary phase diagrams of the Gd-Y [Fig. 9a (Ref 16)] and $\mathrm{GdO}_{1.5}-\mathrm{YO}_{1.5}$ [Fig. 9b (Ref 17)] systems as well as from the suggestive Gd-O phase diagram calculated by McMurray using the CALPHAD methodology [Fig. 9c (Ref 18)]. Usually, such analysis can be additionally supported with data on the thermodynamic stability of selected oxides (Ref 10).

As already mentioned in Introduction, from a comparison of the free energy of the formation of $\mathrm{Y}_{2} \mathrm{O}_{3} \quad(\Delta \bar{G}=-230$ $\mathrm{kcal} / \mathrm{mole}$ ) and $\mathrm{Gd}_{2} \mathrm{O}_{3}(\Delta \bar{G}=-215 \mathrm{kcal} / \mathrm{mole}$ ) (Ref 10) as well as from the character of the temperature dependencies $\Delta \bar{G}=f(T)$ depicted for these oxides in the Ellingham diagram 
of the work ( $\mathrm{Ref} 10$ ), one may suggest that $\mathrm{Y}_{2} \mathrm{O}_{3}$ should be more stable than $\mathrm{Gd}_{2} \mathrm{O}_{3}$, and thus it is difficult to explain the reason for significant structural changes in the $\mathrm{Gd} / \mathrm{Y}_{2} \mathrm{O}_{3}$ couple experimentally evidenced after wettability testing. Taking into account the results of this study on chemical composition of interfacial layer rich in $\mathrm{Gd}$ and $\mathrm{O}$, it can not be completely excluded that the following direct redox reaction may take place during wetting test:

$2 \mathrm{Gd}+\mathrm{Y}_{2} \mathrm{O}_{3}=\mathrm{Gd}_{2} \mathrm{O}_{3}+2 \mathrm{Y}$.

However, the value of Gibbs energy for the above reaction $\left(\Delta G_{\mathrm{r}}\right)$, calculated in this study with the HSC software and the database contained therein (Ref 19) for a temperature of $1362{ }^{\circ} \mathrm{C}$, showed that $\Delta G_{\mathrm{r}}$ is positive and amounts to $14 \mathrm{kcal} / \mathrm{mole}$, i.e., the formation of the $\mathrm{Gd}_{2} \mathrm{O}_{3}$ phase according to the redox reaction (1) is rather unlikely.

Considering the fact that the $\mathrm{Gd}_{2} \mathrm{O}_{3}-\mathrm{Y}_{2} \mathrm{O}_{3}$ quasibinary phase diagram is well established (e.g., Ref 17) and there are no any reports on ternary oxides in the $\mathrm{Gd}_{2} \mathrm{O}_{3}-\mathrm{Y}_{2} \mathrm{O}_{3}$ system, the results of structural examinations are of a great importance for the explanation of the mechanism of high-temperature interaction taking place in the $\mathrm{Gd} / \mathrm{Y}_{2} \mathrm{O}_{3}$ system.

Both optical microscopy (Fig. 6) and scanning electron microscopy (Fig. 7 and 8) showed the occurrence of a deep crater in the $\mathrm{Y}_{2} \mathrm{O}_{3}$ substrate under the solidified drop and the presence of new phases in initially pure Gd sample. Taking into account that the drop matrix became rich in oxygen and yttrium, particularly near the substrate, and all precipitates in

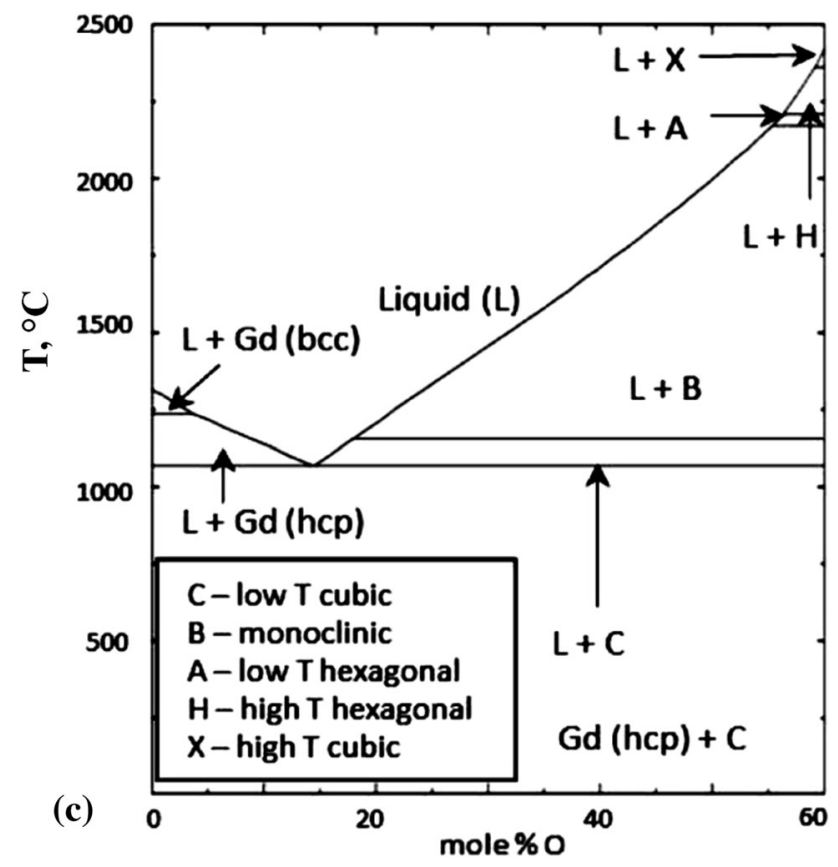

Fig. 9 continued

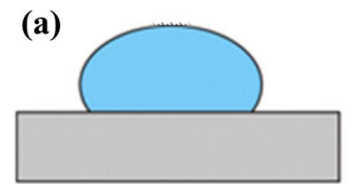

(b)

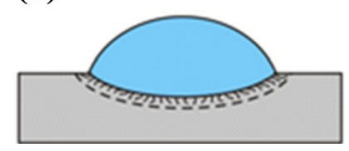

the drop also contain high amounts of yttrium and oxygen, we may conclude that the formation of a deep crater in the substrate is associated with a strong dissolution of yttria in molten Gd while the new phases were precipitated from Y-and $\mathrm{O}$-saturated melt $\mathrm{Gd}(\mathrm{Y}, \mathrm{O})$ during its solidification. Structure examination also shows that the heterogeneous nucleation of new phases takes place both at the drop/substrate interface and on the surface of the drop. Since the needle-like precipitates in the $2 \mathrm{PL}$ area are rich in $\mathrm{Y}$ and they contain $\mathrm{Gd}$ and $\mathrm{O}$ we suggest that they present $\mathrm{Y}_{2} \mathrm{O}_{3}$-based phase, designated as $(\mathrm{Y}, \mathrm{Gd})_{2} \mathrm{O}_{3}$ and formed after wetting tests during cooling of the $\mathrm{Gd}(\mathrm{Y}, \mathrm{O})$ melt saturated with $\mathrm{Y}$ and $\mathrm{O}$ at high temperature. Therefore, the phenomenon responsible for high-temperature interaction and phase transformations in the $\mathrm{Gd} / \mathrm{Y}_{2} \mathrm{O}_{3}$ couple is related to dissolution-reprecipitation mechanism but not with direct interfacial reactions. Moreover, we suggest that the Gdrich discontinuous oxide layer containing $\mathrm{Y}$, well distinguished at the drop/substrate interface (Fig. 8) as well as individual precipitates at the drop surface of similar chemical composition, correspond to the $(\mathrm{Gd}, \mathrm{Y})_{2} \mathrm{O}_{3}$ phase. Although this phase is based on $\mathrm{Gd}_{2} \mathrm{O}_{3}$, it was not reactively formed and represents the residual fragments of primary (native) gadolinium oxide film, in which the $\mathrm{Y}_{2} \mathrm{O}_{3}$ substrate was dissolved during the hightemperature test.

From the analysis of available binary phase diagrams, it has to be emphasized that the $\mathrm{Gd} / \mathrm{Y}_{2} \mathrm{O}_{3}$ system is unique since both Gd and $\mathrm{Y}$ as well as their oxides $\mathrm{Gd}_{2} \mathrm{O}_{3}$ and $\mathrm{Y}_{2} \mathrm{O}_{3}$ show unlimited solubility in both liquid and solid states. That is why high-temperature interaction in the $\mathrm{Gd} / \mathrm{Y}_{2} \mathrm{O}_{3}$ sessile drop couple is dominated by a strong dissolution of $\mathrm{Y}_{2} \mathrm{O}_{3}$ both in the liquid metal and in primary gadolinium oxide covering the Gd sample. Subsequently, it results in the formation of a deep crater in the substrate and new phases that correspond to solid solutions, i.e., $\mathrm{Gd}(\mathrm{Y}),(\mathrm{Y}, \mathrm{Gd})_{2} \mathrm{O}_{3}$ and $(\mathrm{Gd}, \mathrm{Y})_{2} \mathrm{O}_{3}$. It is worth to mention that at this stage of the research, it is impossible to distinguish a clear difference between two solid solutions, $(\mathrm{Gd}, \mathrm{Y})_{2} \mathrm{O}_{3}$ and $(\mathrm{Y}, \mathrm{Gd})_{2} \mathrm{O}_{3}$, due to unlimited solubility between $\mathrm{Y}_{2} \mathrm{O}_{3}$ and $\mathrm{Gd}_{2} \mathrm{O}_{3}$.

A strong dissolution of the substrate in liquid metal is the main reason why the final contact angle measured in this study $\theta_{\mathrm{f}}{ }^{*}=33^{\circ}$ should be considered as apparent value because the real position of the drop/substrate interface is hidden due to the formation a deep crater in the substrate. Moreover, the position of the triple line is additionally affected by a strong liquid metal penetration inside the substrate.

Based on the available literature data and research conducted in this work, the following mechanism of hightemperature interaction in the $\mathrm{Gd} / \mathrm{Y}_{2} \mathrm{O}_{3}$ system during sessile drop test has been proposed, and it is schematically shown in Fig. 10. The interaction starts from melting Gd sample on the $\mathrm{Y}_{2} \mathrm{O}_{3}$ substrate, followed by breaking of chemical bonds in the $\mathrm{Y}_{2} \mathrm{O}_{3}$ oxide and substrate dissolution in liquid gadolinium (Fig. 10a). This process is accompanied by metal penetration into the ceramic along grain boundaries of the $\mathrm{Y}_{2} \mathrm{O}_{3}$ substrate (Fig. 10b) to form a liquid metal penetration zone (LMP). The

(c)

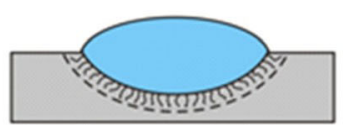

(d)

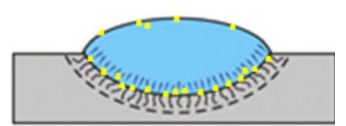

Fig. 10 Schematic presentation of the mechanism of interaction in $\mathrm{Gd} / \mathrm{Y}_{2} \mathrm{O}_{3}$ system 
observed dissolution of $\mathrm{Y}_{2} \mathrm{O}_{3}$ substrate can be explained by the analysis of the hypothetical Gd-O equilibrium system (Ref 18), which shows that up to 25 at.\% of oxygen can be dissolved in liquid gadolinium at a temperature of $T_{\exp }=1362{ }^{\circ} \mathrm{C}$. At the same temperature, the solubility of yttrium in $\mathrm{Gd}$ is about $8 \mathrm{~mol}$ percent in the regular BCC phase and about 30 mol percent in the hexagonal $\mathrm{CPH}$ phase. As a result of the dissolution of the $\mathrm{Y}_{2} \mathrm{O}_{3}$ substrate, a crater is formed in the substrate just under the drop, while the initially pure Gd drop changes its chemical composition to the $\mathrm{Gd}(\mathrm{Y}, \mathrm{O})$ liquid solution (Fig. 10b, c and d). In this stage of interaction, primary oxide film covering the $\mathrm{Gd}$ sample may dissolve yttrium to form the $(\mathrm{Gd}, \mathrm{Y})_{2} \mathrm{O}_{3}$ solid solution.

Upon cooling, oxygen solubility in the liquid Gd decreases rapidly. Therefore, oxygen present in the liquid is rejected either by heterogeneous nucleation of the $(\mathrm{Gd}, \mathrm{Y})_{2} \mathrm{O}_{3}$ crystals both at the drop surface and at the drop/substrate interface or by their homogeneous nucleation at the residual fragments of primary gadolinium oxide film with dissolved yttrium (Fig. 10d). Consequently, the area around the $(\mathrm{Gd}, \mathrm{Y})_{2} \mathrm{O}_{3}$ precipitates becomes depleted in oxygen, while the area in the drop near the substrate, especially in its crater, becomes oversaturated in yttrium. Thus, in the next step of cooling, it makes possible the heterogeneous nucleation and growth of the $(\mathrm{Y}, \mathrm{Gd})_{2} \mathrm{O}_{3}$ phase in the form of needles surrounded by almost pure Gd (Fig. 10d).

The phenomenon of significant substrate dissolution in liquid metal, often observed in metal/metal systems, has also been reported in some metal/non-oxide ceramic systems, e.g., in $\mathrm{Au}-\mathrm{Ni} / \mathrm{ZrB}_{2}(\operatorname{Ref} 20), \mathrm{Ni} / \mathrm{SiC}(\operatorname{Ref} 21)$, and Ni/TiB $2(\operatorname{Ref} 22)$. The results of this study demonstrate that the dissolutive wetting can be a leading mechanism of interaction of liquid metals not only with metallic materials or metallic-like compounds such as metal borides, carbides, and nitrides, but also with oxides.

\section{Conclusions}

Experimental study of the high-temperature interaction between liquid gadolinium and yttrium oxide substrate performed under an inert atmosphere upon heating to and at a temperature $1362{ }^{\circ} \mathrm{C}$ shows a good wettability in the $\mathrm{Gd} / \mathrm{Y}_{2} \mathrm{O}_{3}$ system with a final value of the contact angle $\theta_{\mathrm{f}}^{*}=33^{\circ}$. However, this value should be considered as apparent one because the real position of the drop/substrate interface is hidden due to the formation of a deep crater in the substrate, while the position of the triple line is affected by a strong liquid metal penetration inside the substrate. The contact angle measured at the triple point on the cross section of solidified sessile drop couple was $\theta_{\mathrm{f}}=70^{\circ}$, and it is considered as to the more reliable value that reflects the wetting properties of the $\mathrm{Gd} / \mathrm{Y}_{2} \mathrm{O}_{3}$ couple at $1355-1362{ }^{\circ} \mathrm{C}$. Whatever the real contact angle is, the results of this study leave no doubt about a good wetting in the $\mathrm{Gd} / \mathrm{Y}_{2} \mathrm{O}_{3}$ system, in which dissolutive wetting mechanism, typical for metal/ metal systems, is responsible for significant structural changes in the $\mathrm{Gd} / \mathrm{Y}_{2} \mathrm{O}_{3}$ couple during the high-temperature interaction. This is related to the specific situation, where the unlimited solubility occurs both between pure Gd and Y as well as between their oxides. Therefore, the use of yttria either as a bulk material or a protective coating in contact with metallic melts rich in Gd, particularly for measurements their thermophysical properties by container- or substrateassisted methods, should be done with care and efforts to decrease the contact area and the contact time.

The above findings, formulated from experimental work, show that when information on the phase equilibria in the metal/refractory systems is missing, for the selection of a proper refractory resistant to aggressive attract of a molten metal, the analysis of the Ellingham diagram of the stability of compounds is insufficient and it must be assisted with detailed experimental studies of high-temperature interaction between the metal and the selected refractory.

\section{Acknowledgments}

This study was done in the frame of collaboration program between the German Academic Exchange Service DAAD and the Ministry of Science and Higher Education of Poland. Financial supports from the National Science Centre of Poland (program HARMONIA, Project No. 193624) and the German Academic Exchange Service DAAD (Project No. DAAD-56269397) are acknowledged. The authors acknowledge M.Sc. Janina Radzikowska and Dr. Rafał Nowak for technical assistance in structural characterization.

\section{Open Access}

This article is distributed under the terms of the Creative Commons Attribution 4.0 International License (http://creativecommons.org/ licenses/by/4.0/), which permits unrestricted use, distribution, and reproduction in any medium, provided you give appropriate credit to the original author(s) and the source, provide a link to the Creative Commons license, and indicate if changes were made.

\section{References}

1. J.L. Waring and J. Schneider, Phase Equilibrium Relationships in the System $\mathrm{Gd}_{2} \mathrm{O}_{3}-\mathrm{TiO}_{2}$, J. Res. Natl. Stand. Sect. A, 1965, 69A(3), p 255261

2. D. Klimm, I.A. dos Santos, I.M. Ranieri, and S.L. Baldochi, Phase equilibria and crystal growth for $\mathrm{LiREF}_{4}$ scheelite crystals, in Materials Research Society symposia proceedings, 2009, 1111-D01-07

3. C. Wang, M. Zinkevich, and F. Aldinger, Phase Diagrams and Thermodynamics of Rare-Earth-Doped Zirconia Ceramics, Pure Appl. Chem., 2007, 79(10), p 1731-1753

4. S. Schmitz, H.-G. Lindenkreuz, W. Löser, and B. Büchner, Liquid Phase Separation, Solidification and Phase Transformations of Gd-Ti and Gd-Ti-Al-Cu Alloys, Calphad, 2013, 44, p 21-25

5. P. Turalska, N. Sobczak, A. Polkowska, G. Bruzda, A. Kudyba, I. Kaban, N. Mattern, and J. Eckert, Wettability and Reactivity of Liquid Gd in Contact with $\mathrm{Al}_{2} \mathrm{O}_{3}$ Ceramics, Surf. Eng., 2017, 22(4), p 41-48

6. N. Sobczak, P. Turalska, M. Homa, A. Siewiorek, G. Bruzda, R. Nowak, A. Kudyba, I. Kaban, N. Mattern, and J. Eckert, High temperature interaction between liquid Gd-containing alloys and selected oxides, in Proceedings of the 72nd World Foundry Congress, Nagoya, 2016

7. I. Kaban, R. Nowak, O. Shuleshova, B. Korpala, G. Bruzda, A. Siewiorek, J.H. Han, N. Sobczak, N. Mattern, and J. Eckert, Sessile Drop Study of Gd-Ti Monotectic Alloys on Ceramic Substrates: Phase Transformations, Wetting and Reactivity, J. Mater. Sci., 2012, 47, p 8381-8386

8. P. Turalska, M. Homa, G. Bruzda, N. Sobczak, I. Kaban, N. Mattern, and J. Eckert, Wetting Behavior and Reactivity Between Liquid Gd and ZrO2 Substrate, J. Min. Metall. B, 2017, 53(3), p 285-293 
9. P. Turalska, M. Homa, R. Nowak, G. Bruzda, N. Sobczak, I. Kaban, N. Mattern, and J. Eckert, Wettability, Reactivity and Interfaces in the Gd/ $\mathrm{TiO}_{2}$ System, Trans. Foundry Res. Inst., 2017, LVII(4), p 303-308

10. T.B. Reed, Free Energy Formation of Binary Compounds, MIT Press, Cambridge, 1971

11. N. Sobczak, R. Nowak, W. Radziwill, J. Budzioch, and A. Glenz, Experimental Complex for Investigations of High Temperature Capillarity Phenomena, Mater. Sci. Eng. A, 2008, 495(1-2), p 43-49

12. L. Liggieri and A. Passerone, An Automatic Technique for Measuring the Surface Tension of Liquid Metals, High Temp. Technol., 1989, 7(2), p 82-86

13. ASTRA Reference Book, Oct. 2007, IENRI, Report

14. http://periodictable.com/Elements/064/data.html, Accessed 19 Dec 2018

15. https://www.matbase.com/material-categories/ceramics-and-glasses/cry stalline/technical/zirconium-dioxides/material-properties-of-zirconiumdioxide-yttrium-oxide-stabilized-zro2-y2o3.html?highlight=WyJ5Mm8 zIl0=\#properties, Accessed 28 Feb 2018

16. K.A. Geschenidner and F.W. Calderwood, The Gd-Y (GadoliniumYttrium) System, Bull. Alloy Phase Diagr., 1983, 4(2), p 167-168

17. MTDATA - Phase Diagram Software from the National Physical Laboratory Calculated $\mathrm{Gd}_{2} \mathrm{O}_{3}-\mathrm{Y}_{2} \mathrm{O}_{3}$ phase diagram. http://resource.np 1.co.uk/mtdata/gdyo.htm. Accessed 22 Feb 2018
18. J.W. McMurray, Thermodynamic Modeling of Uranium and Oxygen Containing Ternary Systems with Gadolinium, Lanthanum, and Thorium, $\mathrm{PhD}$ Thesis, University of Tennessee. $\mathrm{h}$ ttp://trace.tennessee.edu/utk_graddiss/3152/, 2014. Accessed 18 May 2017

19. HSC Chemistry ${ }^{\circledR}$ 6.0-Software Copyright $($ - by Outotec Research Oy, Finland, ISBN 13:978-952-9507-12-2

20. R. Voytovych, A. Koltsov, F. Hodaj, and N. Eustathopoulos, Reactive vs Non-reactive Wetting of $\mathrm{ZrB}_{2}$ by Azeotropic Au-Ni, Acta Mater., 2007, 55, p 6316-6321

21. C. Rado, S. Kalogeropoulou, and N. Eustathopoulos, Wetting and Bonding of Ni-Si Alloys on Silicon Carbide, Acta Mater., 1999, 47(2), p 461-473

22. L. Xi, I. Kaban, R. Nowak, G. Bruzda, N. Sobczak, and J. Eckert, Wetting, Reactivity, and Phase Formation at Interfaces Between Ni-Al Melts and $\mathrm{TiB}_{2}$ Ultrahigh-Temperature Ceramic, J. Am. Ceram. Soc., 2017, 110(2), p 911-918

Publisher's Note Springer Nature remains neutral with regard to jurisdictional claims in published maps and institutional affiliations. 